EGU2020-13690

https://doi.org/10.5194/egusphere-egu2020-13690

EGU General Assembly 2020

(c) Author(s) 2021. This work is distributed under

the Creative Commons Attribution 4.0 License.

\title{
On the scaling between precursory moment release and earthquake magnitude: Insights from the laboratory.
}

\author{
Mateo Acosta ${ }^{1}$, Francois Passelègue ${ }^{1}$, Alexandre Schubnel ${ }^{2}$, Raúl Madariaga ${ }^{2}$, and Marie Violay ${ }^{1}$ \\ ${ }^{1}$ EPFL, LEMR, Lausanne, Switzerland (mateo.acosta@epfl.ch) \\ ${ }^{2}$ Laboratoire de Géologie, ENS, Paris, France
}

Recent seismological observations highlighted that both aseismic silent slip and/or foreshock sequences can precede large earthquake ruptures (Tohoku-Oki, 2011, Mw 9.0 (Kato et al., 2012); Iquique, 2014, Mw 8.1 (Ruiz et al, 2014; Socquet et al., 2017); Illapel, 2015, Mw 8.3 (Huang and Meng, 2018); Nicoya, 2012, Mw 7.6 (Voss et al., 2018)). However, the evolution of such precursory markers during earthquake nucleation remains poorly understood. Here, we report for the first time, experimental results regarding the nucleation of laboratory earthquakes (stick slip events) conducted on Westerly Granite saw-cut samples under both dry and fluid pressure conditions. Experiments were conducted under stress conditions representative of the upper continental crust, i.e confining pressures from 50 to $95 \mathrm{MPa}$; fluid pressures (water) ranging from 0 to $45 \mathrm{MPa}$.

At a given effective confining pressure, different precursory slip behaviors are observed. In dry conditions, we observe that slip evolves exponentially up to the main instability and is escorted by an exponential increase of acoustic emissions. With pressurized fluids, precursory slip evolves first exponentially then switches to a power law of time. There, precursory slip remains silent, independently of the fluid pressure level. The temporal evolution of precursory fault slip and seismicity are controlled by the fault's environment, limiting its prognostic value. Nevertheless, we show that, independently of the fault conditions, the total precursory moment release scales with the co-seismic moment of the main instability. The relation follows a semi- empirical scaling relationship between precursory and co-seismic moment release by combining nucleation theory (Ida, 1972; Campillo and lonescu, 1992) with the scaling between fracture energy and co-seismic slip which has been demonstrated experimentally (Nielsen et al., 2016; Passelègue et al., 2016), theoretically (Viesca and Garagash; 2015) and by natural observations (Abercrombie and Rice; 2005). We then compile data from natural earthquakes, and show that, over a range of Mw6.0 to Mw9.0 the proposed scaling law holds for natural observations. In summary, the amount of moment released prior to an earthquake is directly related to its magnitude, increasing therefore the detectability of large earthquakes. The scaling relationship between precursory and co-seismic moment should motivate detailed studies of precursory deformation of moderate to large earthquakes. 